\title{
Accuracy analysis and verification of the method for calculation of geodetic problem on earth ellipsoid surface
}

\author{
Jian Dong ${ }^{1}$, Hongchao Ji ${ }^{1,2}$, Lulu Tang ${ }^{1}$, Rencan Peng ${ }^{1}$, Zhiqiang Zhang ${ }^{1}$ \\ ${ }^{1}$ Department of Military Oceanography and Hydrography \& Cartography, Dalian Naval Academy, Dalian 116018, China \\ ${ }^{2}$ Chart Information Centre, Tianjin 300450, China
}

\begin{abstract}
The method for calculation of geodetic problem on earth ellipsoid surface is the basic premise for the realization of high-precision marine delimitation technology. Based on the analysis of the construction principle of the existing solution of geodetic problem method, the algorithm for direct geodetic problem solution(DGPS) based on nested coefficient method and Bessel's inverse geodetic problem solution(IGPS), which are suitable for various distance solutions, are optimized. Then, the experimental verification scheme of the solution of geodetic problem is designed. Finally, the crossing and reducing accuracy of different calculation examples are verified by different geodetic problem solution methods, and the experiment shows that: the verified accuracy of point-position plotting, distance calculation and azimuth calculation meet the requirements of the indexes of high-precision marine delimitation.
\end{abstract}

\section{Introduction}

The geodetic problem solution on earth ellipsoid surface is the technical foundation to realize the selection of territorial sea base point, the distance(length) of the baseline of territorial sea, azimuth calculation and highprecision representation, create the unilateral maritime boundaries (such as the territorial sea, contiguous zone, exclusive economic zone, et al) and double (or multiple) maritime boundaries (such as equidistant/midline and distance isometric lines), as well as compute varieties of sea area, whose precision has great influence on the result of demarcation, and it also is a key and basic technical problems to maintenance the national marine rights and interests according to law ${ }^{[1-3]}$. In view of the complexity of the geodetic problem solution, many scholars proposed a wide variety of formulas and methods of the geodetic problem solution according to different purposes and different computing tools with the development and changes of technologies ${ }^{[4-8]}$. Based on analyzing the advantages and disadvantages of the existing algorithms of geodetic problem solution, we optimized the algorithm of DGPS with nested coefficient method and Bessel's IGPS from the perspective of engineering practice, designed an experimental verification scheme of the geodetic problem solution and verified the effectiveness of the proposed algorithm is by a large number of examples, which provide the bottom technical support for the high-precision marine delimitation on earth ellipsoid surface.

\section{Problem description of geodetic problem solution}

\subsection{The concept of DGPS and IGPS}

\subsubsection{The definition of DGPS}

Given the geodetic coordinates of point $\left(B_{1}, L_{1}\right)$, the geodetic length $S$ from the point $\left(B_{1}, L_{1}\right)$ to another point and the geodetic azimuth $A_{12}$, calculate the geodetic coordinates of another point $\left(B_{2}, L_{2}\right)$ and the reverse azimuth $A_{21}$. This kind of problem is DGPS, which also can be seen as solving the equations:

$$
\left\{\begin{array}{l}
B_{2}=B_{2}\left(B_{1}, L_{1}, S, A_{12}\right) \\
L_{2}=L_{2}\left(B_{1}, L_{1}, S, A_{12}\right) \\
A_{21}=A_{21}\left(B_{1}, L_{1}, S, A_{12}\right)
\end{array} .\right.
$$

\subsubsection{The definition of IGPS}

Given the geodetic coordinates of two points $\left(B_{1}, L_{1}\right)$ and $\left(B_{2}, L_{2}\right)$, calculate the geodetic length $S$ between two points and its direct and reverse azimuth $A_{12}$ and $A_{21}$. This kind of problem is called IGPS, the same as solving the flowing equations: 


$$
\left\{\begin{array}{l}
S=S\left(B_{1}, L_{1}, B_{2}, L_{2}\right) \\
A_{12}=A_{12}\left(B_{1}, L_{1}, B_{2}, L_{2}\right) \\
A_{21}=A_{21}\left(B_{1}, L_{1}, B_{2}, L_{2}\right)
\end{array} .\right.
$$

Recently, the most of exiting DGPS or IGPS methods are suitable for short distance (within $400 \mathrm{~km}$ ), such as the algorithm of DGPS and IGPS with the Gauss Average number; A part of them are suitable for medium distance (400 5000km), such as DGPS and IGPS with Bawuman projection formula; A few others apply to long distances above $5000 \mathrm{~km}$, such as the nested coefficient method, the Bessel's DGPS/IGPS algorithm, etc.

\subsection{Selection of DGPS and IGPS}

Marine delimitation is usually carried out over a large geographical space ${ }^{[3-5][8]}$. Therefore, in order to ensure the good universality of marine delimitation underlying technology on earth ellipsoid surface, we have to select that geodetic problem solution method which is suitable for long distances. In addition, the DGPS and IGPS should be based on different mathematical principles in the precision verification experiment, so that the calculation

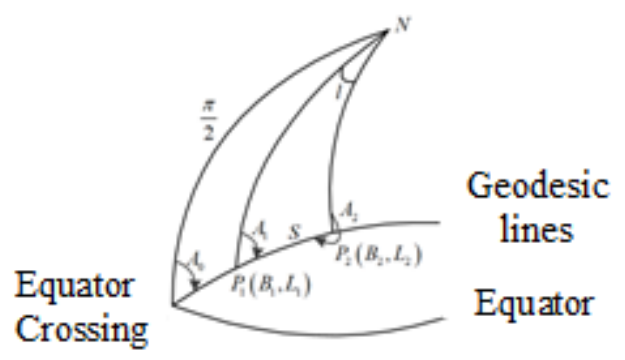

(a) the geodetic elements on the reference ellipsoid surface results can be mutually confirmed, so as to form a mutual check.

Based on the above analysis, we will focus on the algorithm of DGPS with nested coefficient method and Bessel's IGPS which can be used by the underlying technology of marine delimitation on the earth ellipsoid surface and suitable for various distance solutions. Considering that both algorithm of DGPS with nested coefficient method and Bessel's IGPS use the Bessel assistant sphere surface as the transition, the corresponding relation between the reference ellipsoid surface and the Bessel assistant sphere surface is clarified for the convenience of expression.

As shown in Fig. 1(a), $N$ is the pole of the ellipsoid, $p_{1}$ and $p_{2}$ are two points on the ellipsoid surface, which are the geodetic elements on the reference ellipsoid surface. Fig. 1 (b) shows the elements which are transformed to the unit assistant sphere surface from the geodetic elements by the Bessel's projection condition, where the $N^{\prime}$ is spherical poles, $p_{1}{ }^{\prime}$ and $p_{2}{ }^{\prime}$ are projection points of $p_{1}$ and $p_{2}$ respectively.

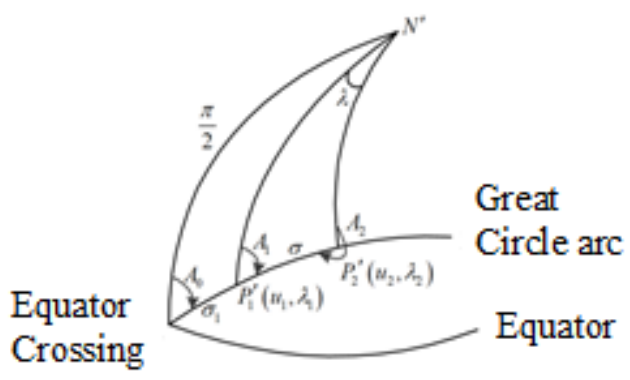

(b) projection on Bessel's assistant sphere surface

Figure 1. Correspondence between reference ellipsoid surface and Bessel assistant sphere surface.

\section{The principle of the algorithm for solution of geodetic problem}

For the parameters of earth ellipsoid, we adopt $a, b$, $\alpha=\frac{a-b}{a}, e=\sqrt{\frac{a^{2}-b^{2}}{a^{2}}}$ and $e^{\prime}=\sqrt{\frac{a^{2}-b^{2}}{b^{2}}}$ to represent major semi-axis, minor semi-axis, flattening, the first eccentricity and the second eccentricity, and $\rho^{\prime \prime}$ denote the number of seconds per unit radian, the above variables will not be explained in the following formulas.

\subsection{The DGPS with nested coefficient method}

The differential equation of the geoid on the earth's ellipsoid surface is given as follows:

$$
\left\{\begin{array}{l}
\frac{d B}{d S}=\frac{\cos A}{M} \\
\frac{d L}{d S}=\frac{\sin A}{N \cos B}
\end{array},\right.
$$

where the $M$ and $N$ are the curvature radii of the meridian and prime circle. The differential equation of the great circle arc of the Bessel unit circle spherical surface is given as follows:

$$
\left\{\begin{array}{l}
\frac{d u}{d \sigma}=\cos A \\
\frac{d \lambda}{d \sigma}=\frac{\sin A}{\cos u}
\end{array},\right.
$$

where $\sigma$ represent spherical Angle, $u$ is reduced latitude, $\lambda$ is spherical longitude difference.

In addition, the reduced latitude has a definite correspondence with the geodetic latitude at the same point, and its conversion formula is:

$$
\tan u=\sqrt{1-e^{2}} \tan B \text {. }
$$

The differential-relation equation between the spherical Angle $\sigma$ and geodesic length $S$, spherical longitude difference $\lambda$ and geodetic longitude difference $l$, can be expressed as follows:

$$
\left\{\begin{array}{l}
\frac{d S}{d \sigma}=b \sqrt{1+e^{\prime 2} \sin ^{2} u} \\
\frac{d l}{d \lambda}=\sqrt{1-e^{2} \cos ^{2} u}
\end{array} .\right.
$$


The Equation (6) is expanded according to the ascending power series of $e^{\prime 2}$, and then the nested coefficients are brought in. After integral reduction, the relation between spherical Angle $\sigma$ and the geodesic length $S$ can be obtained:

$$
S=K_{1} b(\sigma-\Delta \sigma),
$$

where the $K_{1}$ and $\Delta \sigma$ can be calculated by Equation (8):

$$
\left\{\begin{array}{l}
t=\left(e^{\prime 2} \sin ^{2} u_{n}\right) / 4 \\
K_{1}=1+t\{1-t[3-t(5-11 t)] / 4\} \\
K_{2}=t\{1-t[2-t(37-94 t) / 8]\} \\
\sigma_{m}=\sigma_{1}+\sigma / 2 \\
\Delta \sigma=K_{2} \sin \sigma\left\{\cos 2 \sigma_{m}+\frac{K_{2}}{4}\left[\cos \sigma \cos 4 \sigma_{m}+\frac{K_{2}}{6}(1+2 \cos 2 \sigma) \cos 6 \sigma_{m}\right]\right\}
\end{array}\right.
$$

where the $K_{1}$ and $K_{2}$ represent the nested coefficient to reduce the length of geodesic lines, and $\Delta \sigma$ is the reduction ellipsoid correction of geodesic length.

In the same way, expand Equation (6) according to the ascending power series of $e^{2}$, and then substitute the nested coefficient. After integral reduction, the relation between spherical longitude difference $\lambda$ and geodetic longitude difference $l$ can be obtained as follows:

$$
l=\lambda-\Delta \lambda .
$$

Similar to the calculation way of $K_{1}$ and $\Delta \sigma$, the $\Delta \sigma$ of Equation (9) can be calculated by Equation (10):

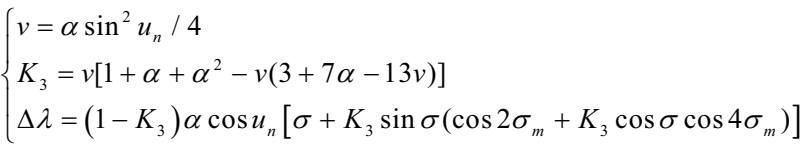

where $K_{3}$ represent the nested coefficient to reduce the geodetic longitude difference, and $\Delta \lambda$ is the reduction ellipsoid correction of geodetic longitude.

In conclusion, the nested coefficient method is the deriving process of three nested coefficients $K_{1}, K_{2}$ and $K_{3}$ to calculate ellipsoid correction and two multiplicative property correction $\Delta \sigma$ and $\Delta \lambda$ by nesting reduction, which start from the differential formula of the Bessel's geodetic problem solution(Equation (6)), along different integration paths, make full use of the multiplicative property of function power and coefficients itself in the expansion of each series. Theoretically, the accuracy of the calculation results can reach $10^{-5}$ "and $1 \mathrm{~mm}$, while the ellipsoid correction calculated by the nested coefficient method is taken to $e^{8}$ or $e^{18}$.

\subsection{The algorithm of Bessel's IGPS}

The basic idea of Bessel's geodetic problem solution is to project the geodetic elements on the earth ellipsoid surface to an assistant sphere surface according to the Bessel projection condition, then implement geodetic problem solution on the assistant sphere surface, and finally convert the results to the earth's ellipsoid surface (as shown in Figure 1). And the key point of this method is to find the relation formula between the geodetic elements on ellipsoid surface and responding elements on the sphere surface.

For the convenience of calculation, Bessel proposed three projection conditions, namely: (1) The geodesic line on the ellipsoid surface is shown as a great circular arc when projected onto a sphere; (2) The azimuth angles of the corresponding points on the geodesic line and the great circular arc are equal; (3) The spherical latitude of any point on the sphere is equal to the reduced latitude of the corresponding point on ellipsoid. From these projection conditions, the Bessel's differential equation can be obtained as follows:

$$
\left\{\begin{array}{l}
\frac{d S}{d \sigma}=a \sqrt{1-e^{2} \cos ^{2} u} \\
\frac{d L}{d \lambda}=\sqrt{1-e^{2} \cos ^{2} u}
\end{array} .\right.
$$

The error pf distance is less than $\pm 0.1 \mathrm{~m}$ while implement Bessel's IGPS within the range of 400 $17000 \mathrm{~km}$. If using the Bessel's IGPS to approximate calculation, within the range of $400 \sim 17000 \mathrm{~km}$, the distance error of approximate calculation with meter level can be less than $\pm 0.5 \mathrm{~m}$, and the distance error of approximate calculation in $100 \mathrm{~m}$ class is less than $50 \mathrm{~m}$.

\section{Precision verification scheme of geodetic problem solution}

According to the related research, the precision index in marine delimitation can be divided into absolute and relative precision index. The absolute precision index is the precision index established on the earth ellipsoid surface, which has nothing to do with map projection and chart scale. However, the relative precision index is the precision index build on chart projection surface, which is related to map projection and chart scale. It is obvious that if you want to meet the requirements of high precision marine delimitation on earth ellipsoid surface, the absolute precision index must be adopted. According to the practical application requirements, the absolute precision index of marine delimitation on the earth ellipsoid surface is determined as follows: (1) Point plotting and capturing accuracy is no greater than $0.01 "$; (2) Distance calculation accuracy is no more than $1 \mathrm{~m}$; (3)The area calculation accuracy is no more than $1 \mathrm{~m}^{2}$; (4) Azimuth calculation Accuracy is no greater than $0.01 "$ ". In this manuscript, we select the examples in current literatures to implement the accuracy verification experiments of nested coefficient DGPS and Bessel's IGPS by the way of crossover and reduction.

The experiment consists of two parts:

Part A: Precision verification of nested coefficient DGPS

Specifically, the examples are calculated by using the nested coefficient DGPS firstly, and the calculating error is obtained by comparing the value calculated in this manuscript and given in the literature. Then, the value calculated and the given conditions are calculated together 
by using the Bessel's IGPS. Finally, the calculated error can be achieved by comparing the value calculated and known conditions. The experimental process is shown in Figure 2.

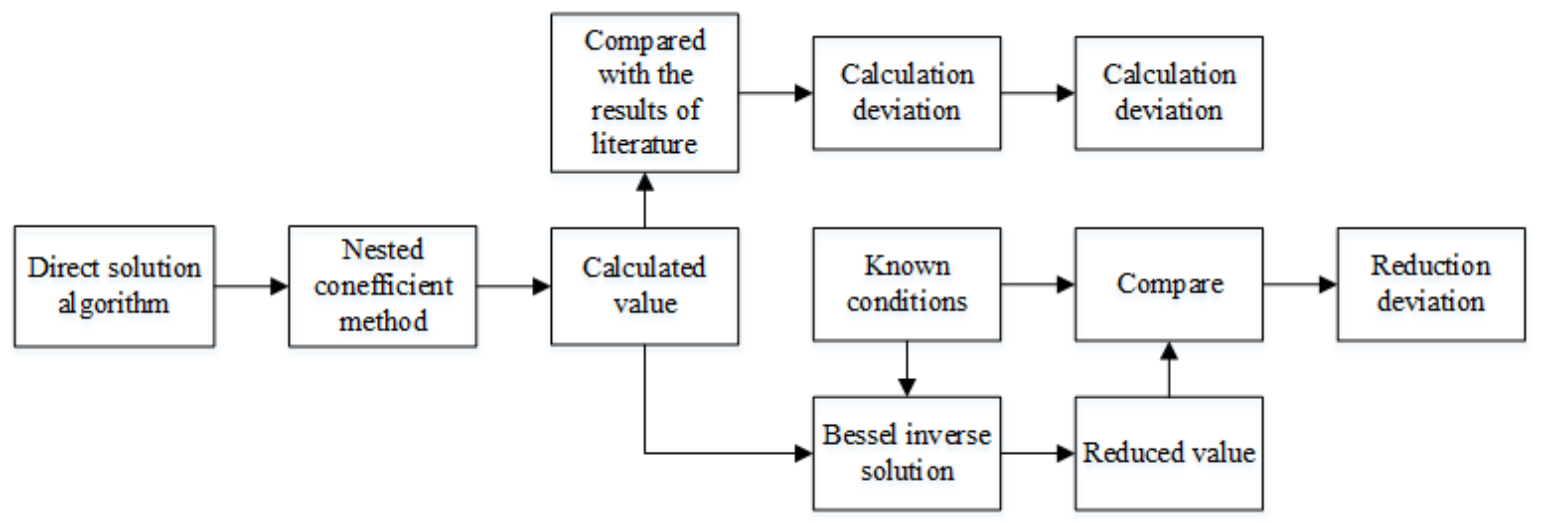

Figure 2. Accuracy verification experiment of nested coefficient DGPS

Part B: Precision verification of Bessel's IGPS

The treatment methods of examples in this part is opposite to the Part A. Namely, the examples are calculated by Bessel's IGPS, and the calculated error can be obtained by comparing the computed value and the result of literature. Then, the computed value and given condition can be calculated together by using the nested coefficient DGPS, and the reduction error can be gained by comparing the calculated value and known condition. The experimental process is shown in Figure 3.

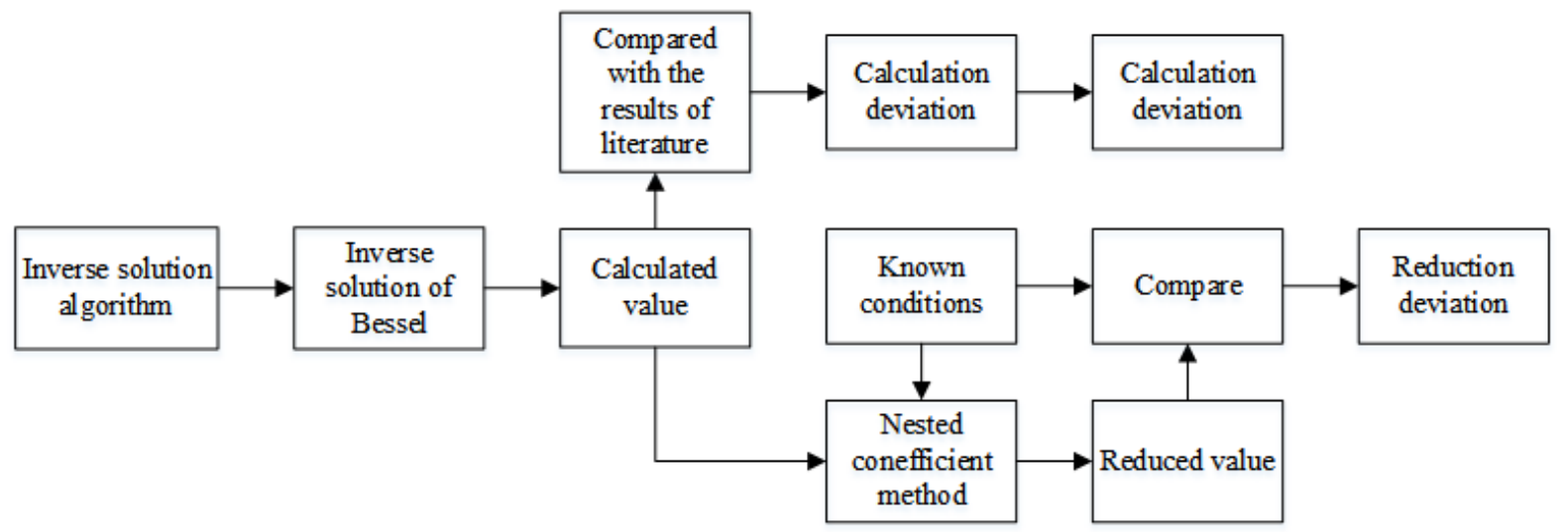

Figure 3. Accuracy verification experiment of Bessel's IGPS

\section{Test and Analysis}

In order to realize the engineering application of geodetic problem solution method on earth ellipsoid surface, we use C\# language and ArcEngine secondary development technology to design and implement the nested coefficient DGPS and Bessel's IGPS, and verify the validity of geodetic problem solution method on earth ellipsoid by employing various examples in reference [9-12]. In the following experimental tables, the $B_{2}^{\prime}, L_{2}^{\prime}$ and $A_{2}^{\prime}$ are the destination coordinate and reverse azimuth of geodesic line computed by proposed algorithms; the $\Delta_{B_{2}^{\prime}}, \Delta_{L_{2}^{\prime}}$ and $\Delta_{A_{2}^{\prime}}$ represents the value differences between the presented algorithm and the algorithms in relevant literature in the calculation of the destination coordinate and reverse azimuth of geodesic line; $S^{\prime}$ and $A_{1}^{\prime}$ are the length and azimuth of geodesic line achieved by proposed algorithm; $\delta_{S^{\prime}}, \delta_{A_{1}^{\prime}}$ and $\delta_{A_{2}}$ represent the numerical differences of the length and direct/reverse azimuths of the geodesic line obtained by one iteration of proposed algorithm (in other words, substitute the result of direct /inverse solution for the formula of inverse /direct solution again); and the $\delta_{B_{2}^{\prime}}$ and $\delta_{L_{2}^{\prime}}$ represent the coordinates differences of geodesic line terminal calculated by one iteration with presented algorithm.

\subsection{Accuracy verification of the nested coefficient DGPS}

\section{Example 1}

The calculation value of Example 1 computed by nested coefficient DGPS and the calculation deviation between the calculation value above and result of reference [9] are shown in Table 1. 
Table 1. Statistics of calculation deviation in Example 1

\begin{tabular}{cccccc}
\hline \multicolumn{2}{c}{ Ellipsoid type } & Hayford & Krasovsky & Krasovsky & Krasovsky \\
\hline \multirow{2}{*}{$\begin{array}{c}\text { Calculation } \\
\text { value }\end{array}$} & $B_{2}^{\prime}$ & $-62^{\circ} 57^{\prime} 03.2039^{\prime \prime}$ & $00^{\circ} 00^{\prime} 00.0002^{\prime \prime}$ & $90^{\circ} 00^{\prime} 00^{\prime \prime}$ & $23^{\circ} 39^{\prime} 23.7430^{\prime \prime}$ \\
& $L_{2}^{\prime}$ & $105^{\circ} 05^{\prime} 38.2985^{\prime \prime}$ & $154^{\circ} 59^{\prime} 59.9996^{\prime \prime}$ & $70^{\circ} 00^{\prime} 00^{\prime \prime}$ & $139^{\circ} 04^{\prime} 35.7736^{\prime \prime}$ \\
& $A_{2}^{\prime}$ & $294^{\circ} 46^{\prime} 41.4839^{\prime \prime}$ & $292^{\circ} 44^{\prime} 34.9922^{\prime \prime}$ & $180^{\circ} 00^{\prime} 00^{\prime \prime}$ & $296^{\circ} 38^{\prime} 33.3197^{\prime \prime}$ \\
$\begin{array}{c}\text { Calculation } \\
\text { deviation }\end{array}$ & $\Delta_{B_{2}^{\prime}}$ & $0.000033^{\prime \prime}$ & $0.00000892348574^{\prime \prime}$ & $0.000^{\prime \prime}$ & $0.00165^{\prime \prime}$ \\
& $\Delta_{L_{2}^{\prime}}$ & $0.001163^{\prime \prime}$ & $0.00074613638^{\prime \prime}$ & $0.000^{\prime \prime}$ & $0.007512^{\prime \prime}$ \\
& $\Delta_{A_{2}^{\prime}}$ & $0.000003^{\prime \prime}$ & $0.0000360248153^{\prime \prime}$ & $0.000^{\prime \prime}$ & $0.001379^{\prime \prime}$ \\
\hline
\end{tabular}

The calculated values in Table 1 and the given conditions in reference [9] were reduced together by the Bessel's IGPS. And then, the value computed and the error reduced between the that value and known condition are shown in Table 2.

Table 2. Statistics of reduction error in Example 1

\begin{tabular}{lccccc}
\hline \multicolumn{2}{c}{ Ellipsoid type } & Hayford & Krasovsky & Krasovsky & Krasovsky \\
\hline $\begin{array}{c}\text { Reduced } \\
\text { value }\end{array}$ & $S^{\prime}$ & $14999999.8595 \mathrm{~m}$ & $15330446.4545 \mathrm{~m}$ & $11661156.7269 \mathrm{~m}$ & $14891567.0522 \mathrm{~m}$ \\
& $A_{1}^{\prime}$ & $140^{\circ} 00^{\prime} 0.0013^{\prime \prime}$ & $72^{\circ} 39^{\prime} 45.8227^{\prime \prime}$ & $00^{\circ} 00^{\prime} 00^{\prime \prime}$ & $56^{\circ} 06^{\prime} 57.0794^{\prime \prime}$ \\
\hline $\begin{array}{c}\text { Reduction } \\
\text { error }\end{array}$ & $A_{2}^{\prime}$ & $294^{\circ} 46^{\prime} 41.4871^{\prime \prime}$ & $292^{\circ} 44^{\prime} 34.9953^{\prime \prime}$ & $180^{\circ} 00^{\prime} 00^{\prime \prime}$ & $2^{\circ} 95^{\circ} 03^{\prime} 48.1667^{\prime \prime}$ \\
\hline$S_{S_{1}^{\prime}}$ & $0.1405 \mathrm{~m}$ & $0.321419 \mathrm{~m}$ & $0.00164967 \mathrm{~m}$ & - \\
\hline
\end{tabular}

\section{Example 2}

The calculation value of Example 2 computed by nested coefficient DGPS and the calculation deviation between the calculation value above and result of reference [10] are shown in Table 3.

Table 3. Statistics of calculation deviation in Example 2

\begin{tabular}{ccccccc}
\hline Ellipsoid type & & Krasovsky & Krasovsky & Krasovsky & Krasovsky & GRS75 \\
\hline Calculated & $B_{2}^{\prime}$ & $40^{\circ} 45^{\prime} 47.9027^{\prime \prime}$ & $43^{\circ} 00^{\prime} 55.8784^{\prime \prime}$ & $37^{\circ} 44^{\prime} 59.9774^{\prime \prime}$ & $-30^{\circ} 29^{\prime} 20.9642^{\prime \prime}$ & $0^{\circ} 00^{\prime} 0.0000^{\prime \prime}$ \\
value & $L_{2}^{\prime}$ & $130^{\circ} 12^{\prime} 01.104^{\prime \prime}$ & $118^{\circ} 10^{\prime} 02.9999^{\prime \prime}$ & $-122^{\circ} 26^{\prime} 00.004^{\prime \prime}$ & $-144^{\circ} 00^{\prime} 55.668^{\prime \prime}$ & $10^{\circ} 00^{\prime} 0.0000^{\prime \prime}$ \\
& $A_{2}^{\prime}$ & $181^{\circ} 50^{\prime} 53.5452^{\prime \prime}$ & $218^{\circ} 11^{\prime} 26.7967^{\prime \prime}$ & $9^{\circ} 01^{\prime} 07.8101^{\prime \prime}$ & $290^{\circ} 32^{\prime} 53.389^{\prime \prime}$ & $89^{\circ} 59^{\prime} 59.9979^{\prime \prime}$ \\
\hline $\begin{array}{c}\text { Calculation } \\
\text { deviation }\end{array}$ & $\Delta_{B_{2}^{\prime}}$ & $0.000 \mathrm{~m}$ & $0.000 \mathrm{~m}$ & $0.000 \mathrm{~m}$ & $0.000 \mathrm{~m}$ & $0.000 \mathrm{~m}$ \\
& $\Delta_{L_{2}^{\prime}}$ & $0.000^{\prime \prime}$ & $0.000^{\prime \prime}$ & $0.00048^{\prime \prime}$ & $0.00094^{\prime \prime}$ & $0.000^{\prime \prime}$ \\
\hline$A_{2}$ & $0.0001^{\prime \prime}$ & $0.000^{\prime \prime}$ & $0.000^{\prime \prime}$ & $0.009^{\prime \prime}$ & $0.0021^{\prime \prime}$ \\
\hline
\end{tabular}

The calculated values in Table 3 and the given conditions in reference [10] were reduced together by the Bessel's IGPS. And then, the value computed and the error reduced between the that value and known condition are shown in Table 4.

Table 4. Statistics of reduction error in Example 2

\begin{tabular}{|c|c|c|c|c|c|c|}
\hline $\begin{array}{l}\text { Ellipsoid } \\
\text { type }\end{array}$ & & Krasovsky & Krasovsky & Krasovsky & Krasovsky & GRS75 \\
\hline \multirow{3}{*}{$\begin{array}{l}\text { Reduced } \\
\text { value }\end{array}$} & $S^{\prime}$ & $80000.0000 \mathrm{~m}$ & $414306.5321 \mathrm{~m}$ & $7999606.1322 \mathrm{~m}$ & $14999999.9899 \mathrm{~m}$ & $10018758.6945 \mathrm{~m}$ \\
\hline & $A_{1}^{\prime}$ & $1^{\circ} 49^{\prime} 43^{\prime \prime}$ & $36^{\circ} 12^{\prime} 01.0264^{\prime \prime}$ & $339^{\circ} 49^{\prime} 56.3843^{\prime \prime}$ & $100^{\circ} 00^{\prime} 0.3342^{\prime \prime}$ & $270^{\circ} 00^{\prime} 0.0021^{\prime \prime}$ \\
\hline & $A_{2}^{\prime}$ & $181^{\circ} 50^{\prime} 53.5451^{\prime \prime}$ & $218^{\circ} 11^{\prime} 26.7967^{\prime \prime}$ & $9^{\circ} 01^{\prime} 07.8104^{\prime \prime}$ & $290^{\circ} 32^{\prime} 53.391^{\prime \prime}$ & $89^{\circ} 59^{\prime} 59.9979^{\prime \prime}$ \\
\hline
\end{tabular}




\begin{tabular}{|c|c|c|c|c|c|c|}
\hline \multirow{3}{*}{$\begin{array}{l}\text { Reduction } \\
\text { error }\end{array}$} & $\delta_{S^{\prime}}$ & $0.000 \mathrm{~m}$ & $0.0059 \mathrm{~m}$ & $0.2478 \mathrm{~m}$ & $0.2101 \mathrm{~m}$ & $0.1885 \mathrm{~m}$ \\
\hline & $\delta_{A_{1}^{\prime}}$ & $0.000^{\prime \prime}$ & $0.0006^{\prime \prime}$ & $0.0007^{\prime \prime}$ & $0.0042^{\prime \prime}$ & $0.0021^{\prime \prime}$ \\
\hline & $\delta_{A_{2}}$ & $0.0001^{\prime \prime}$ & $0.000^{\prime \prime}$ & $0.0003^{\prime \prime}$ & $0.002^{\prime \prime}$ & $0.000^{\prime \prime}$ \\
\hline
\end{tabular}

\section{Example3}

The calculation value of Example 3 computed by nested coefficient DGPS and the calculation deviation between the calculation value above and result of reference [11] are shown in Table 5.

Table 5. Statistics of calculation deviation in Example 3

\begin{tabular}{cccccccc}
\hline \multicolumn{2}{c}{ Ellipsoid type } & Krasovsky & Krasovsky & Bessel & Krasovsky & Krasovsky & GRS75 \\
\hline \multirow{2}{*}{$\begin{array}{c}\text { Calculated } \\
\text { value }\end{array}$} & $B_{2}^{\prime}$ & $40^{\circ} 45^{\prime} 47.9027^{\prime \prime}$ & $43^{\circ} 00^{\prime} 55.8784^{\prime \prime}$ & $55^{\circ} 00^{\prime} 00.001^{\prime \prime}$ & $37^{\circ} 44^{\prime} 59.9774^{\prime \prime}$ & $-30^{\circ} 29^{\prime} 20.9642^{\prime \prime}$ & $90^{\circ} 00^{\prime} 00.0000^{\prime \prime}$ \\
& $L_{2}^{\prime}$ & $130^{\circ} 12^{\prime} 01.104^{\prime \prime}$ & $118^{\circ} 10^{\prime} 02.9999^{\prime \prime}$ & $9^{\circ} 59^{\prime} 59.9973^{\prime \prime}$ & $-122^{\circ} 26^{\prime} 00.0048^{\prime \prime}$ & $215^{\circ} 59^{\prime} 04.332^{\prime \prime}$ & $100^{\circ} 00^{\prime} 00.0000^{\prime \prime}$ \\
& $A_{2}^{\prime}$ & $181^{\circ} 50^{\prime} 53.5452^{\prime \prime}$ & $218^{\circ} 11^{\prime} 26.7967^{\prime \prime}$ & $216^{\circ} 45^{\prime} 07.3899^{\prime \prime}$ & $9^{\circ} 01^{\prime} 07.8101^{\prime \prime}$ & $290^{\circ} 32^{\prime} 53.389^{\prime \prime}$ & $180^{\circ} 00^{\prime} 00.0000^{\prime \prime}$ \\
\hline \multirow{2}{*}{$\begin{array}{c}\text { Calculation } \\
\text { deviation }\end{array}$} & $\Delta_{B_{2}^{\prime}}$ & $0.000^{\prime \prime}$ & $0.00001^{\prime \prime}$ & $0.001^{\prime \prime}$ & $0.0009^{\prime \prime}$ & $0.00008^{\prime \prime}$ & $0.000^{\prime \prime}$ \\
& $\Delta_{L_{2}^{\prime}}$ & $0.00003^{\prime \prime}$ & $0.00009^{\prime \prime}$ & $0.0026^{\prime \prime}$ & $0.00072^{\prime \prime}$ & $0.0059^{\prime \prime}$ & $0.000^{\prime \prime}$ \\
& $\Delta_{\dot{A}_{2}}$ & $0.0001^{\prime \prime}$ & $0.000^{\prime \prime}$ & $0.0011^{\prime \prime}$ & $0.000^{\prime \prime}$ & $0.0006^{\prime \prime}$ & $0.000^{\prime \prime}$ \\
\hline
\end{tabular}

The calculated values in Table 5 and the given conditions in reference [11] were reduced together by the Bessel's IGPS. And then, the value computed and the error reduced between the that value and known condition are shown in Table 6.

Table 6. Statistics of reduction error in Example 3

\begin{tabular}{|c|c|c|c|c|c|c|c|}
\hline \multicolumn{2}{|c|}{ Ellipsoid type } & Krasovsky & Krasovsky & Bessel & Krasovsky & Krasovsky & GRS75 \\
\hline \multirow{3}{*}{$\begin{array}{l}\text { Reduced } \\
\text { value }\end{array}$} & $S^{\prime}$ & $80000.0000 \mathrm{~m}$ & $414306.5321 \mathrm{~m}$ & $1320284.3445 \mathrm{~m}$ & $7999606.1322 \mathrm{~m}$ & $14999999.9899 m$ & $10001970.4071 \mathrm{~m}$ \\
\hline & $A_{1}^{\prime}$ & $1^{\circ} 49^{\prime} 43.0018^{\prime \prime}$ & $36^{\circ} 12^{\prime} 01.0264^{\prime \prime}$ & $29^{\circ} 03^{\prime} 15.4504^{\prime \prime}$ & $339^{\circ} 49^{\prime} 56.3843^{\prime \prime}$ & $100^{\circ} 00^{\prime} 00.3342^{\prime \prime}$ & $00^{\circ} 00^{\prime} 00.0000^{\prime \prime}$ \\
\hline & $A_{2}^{\prime}$ & $181^{\circ} 50^{\prime} 53.547^{\prime \prime}$ & $218^{\circ} 11^{\prime} 26.796^{\prime \prime}$ & $216^{\circ} 45^{\prime} 07.3892^{\prime \prime}$ & $9^{\circ} 01^{\prime} 07.8104^{\prime \prime}$ & $290^{\circ} 32^{\prime} 53.391^{\prime \prime}$ & $180^{\circ} 00^{\prime} 00.0000^{\prime \prime}$ \\
\hline \multirow{3}{*}{$\begin{array}{l}\text { Reduction } \\
\text { error }\end{array}$} & $\delta_{S^{\prime}}$ & $0.000 \mathrm{~m}$ & $0.0059 \mathrm{~m}$ & $0.0205 \mathrm{~m}$ & $0.2478 \mathrm{~m}$ & $0.2101 \mathrm{~m}$ & $0.0006 \mathrm{~m}$ \\
\hline & $\delta_{A_{1}^{\prime}}$ & $0.0018^{\prime \prime}$ & $0.0006^{\prime \prime}$ & $0.0006^{\prime \prime}$ & $0.0007^{\prime \prime}$ & $0.0042^{\prime \prime}$ & $0.000^{\prime \prime}$ \\
\hline & $\delta_{A_{2}}$ & $0.0018^{\prime \prime}$ & $0.0007^{\prime \prime}$ & $0.0007^{\prime \prime}$ & $0.0003^{\prime \prime}$ & $0.002^{\prime \prime}$ & $0.000^{\prime \prime}$ \\
\hline
\end{tabular}

\section{Example 4}

The calculation value of Example 4 computed by nested coefficient DGPS and the calculation deviation between the calculation value above and result of reference [12] are shown in Table 7.

Table 7. Statistics of calculation deviation in Example 4

\begin{tabular}{|c|c|c|c|c|c|c|}
\hline \multicolumn{2}{|c|}{ Ellipsoid type } & CGCS2000 & CGCS2000 & CGCS2000 & CGCS2000 & CGCS2000 \\
\hline \multirow{3}{*}{$\begin{array}{l}\text { Calculated } \\
\text { value }\end{array}$} & $B_{2}^{\prime}$ & $35^{\circ} 00^{\prime} 29.4092^{\prime \prime}$ & $35^{\circ} 04^{\prime} 54.0613^{\prime \prime}$ & $35^{\circ} 48^{\prime} 57.5209^{\prime \prime}$ & $43^{\circ} 03^{\prime} 30.4629^{\prime \prime}$ & $48^{\circ} 10^{\prime} 18.9129^{\prime \prime}$ \\
\hline & $L_{2}^{\prime}$ & $114^{\circ} 00^{\prime} 16.6678^{\prime \prime}$ & $114^{\circ} 02^{\prime} 46.8278^{\prime \prime}$ & $114^{\circ} 28^{\prime} 03.4512^{\prime \prime}$ & $119^{\circ} 10^{\prime} 24.9707^{\prime \prime}$ & $254^{\circ} 39^{\prime} 31.4649^{\prime \prime}$ \\
\hline & $A_{2}^{\prime}$ & $205^{\circ} 00^{\prime} 09.5613^{\prime \prime}$ & $205^{\circ} 01^{\prime} 35.7859^{\prime \prime}$ & $205^{\circ} 16^{\prime} 15.4113^{\prime \prime}$ & $208^{\circ} 16^{\prime} 02.4216^{\prime \prime}$ & $328^{\circ} 45^{\prime} 15.5398^{\prime \prime}$ \\
\hline \multirow{3}{*}{$\begin{array}{l}\text { Calculation } \\
\text { deviation }\end{array}$} & $\Delta_{B_{2}^{\prime}}$ & $0.00038^{\prime \prime}$ & $0.0004^{\prime \prime}$ & $0.00036^{\prime \prime}$ & $0.00026^{\prime \prime}$ & - \\
\hline & $\Delta_{L_{2}^{\prime}}$ & $0.0002^{\prime \prime}$ & $0.00021^{\prime \prime}$ & $0.00023^{\prime \prime}$ & $0.00019^{\prime \prime}$ & - \\
\hline & $\Delta_{A_{2}^{\prime}}$ & $0.00009^{\prime \prime}$ & $0.00013^{\prime \prime}$ & $0.00016^{\prime \prime}$ & - & - \\
\hline
\end{tabular}


The calculated values in Table 7 and the given conditions in reference [12] were reduced together by the Bessel's IGPS. And then, the value computed and the error reduced between the that value and known condition are shown in Table 8.

Table 8. Statistics of reduction error in Example 4

\begin{tabular}{ccccccc}
\hline \multicolumn{2}{c}{ Ellipsoid type } & CGCS2000 & CGCS2000 & CGCS2000 & CGCS2000 & CGCS2000 \\
\hline \multirow{2}{*}{$\begin{array}{c}\text { Reduced } \\
\text { value }\end{array}$} & $S^{\prime}$ & $1000.0003 \mathrm{~m}$ & $10000.0003 \mathrm{~m}$ & $99999.9999 \mathrm{~m}$ & $999999.9884 \mathrm{~m}$ & $9999999.7821 \mathrm{~m}$ \\
& $A_{1}^{\prime}$ & $24^{\circ} 59^{\prime} 59.9981^{\prime \prime}$ & $25^{\circ} 00^{\prime} 0.0071^{\prime \prime}$ & $24^{\circ} 59^{\prime} 59.998^{\prime \prime}$ & $24^{\circ} 59^{\prime} 59.9993^{\prime \prime}$ & $25^{\circ} 00^{\prime} 0.0024^{\prime \prime}$ \\
\hline & $A_{2}^{\prime}$ & $205^{\circ} 00^{\prime} 09.5593^{\prime \prime}$ & $205^{\circ} 01^{\prime} 35.793^{\prime \prime}$ & $205^{\circ} 16^{\prime} 15.4093^{\prime \prime}$ & $208^{\circ} 16^{\prime} 02.4208^{\prime \prime}$ & $328^{\circ} 45^{\prime} 15.5366^{\prime \prime}$ \\
$\begin{array}{c}\text { Reduction } \\
\text { error }\end{array}$ & $\delta_{S^{\prime}}$ & $0.0003 \mathrm{~m}$ & $0.0003 \mathrm{~m}$ & $0.0001 \mathrm{~m}$ & $0.0116 \mathrm{~m}$ & $0.2179 \mathrm{~m}$ \\
& $\delta_{A_{1}^{\prime}}$ & $0.0019^{\prime \prime}$ & $0.0071^{\prime \prime}$ & $0.002^{\prime \prime}$ & $0.0007^{\prime \prime}$ & $0.0024^{\prime \prime}$ \\
\hline$A_{A^{\prime}}$ & $0.002^{\prime \prime}$ & $0.00697^{\prime \prime}$ & $0.002^{\prime \prime}$ & $0.0008^{\prime \prime}$ & $0.0032^{\prime \prime}$ \\
\hline
\end{tabular}

\subsection{Accuracy verification of the algorithm for inverse solution of Bessel's geodetic problem}

\section{Example 5}

The calculation values of example 5 obtained by Bessel's
IGPS and the calculation deviation between the calculation value above and result of reference [9] are shown in Table 9.

Table 9. Statistics of calculation deviation in Example 5

\begin{tabular}{cccccc}
\hline \multirow{2}{*}{ Ellipsoid type } & & Hayford & Krasovsky & Krasovsky & Krasovsky \\
\cline { 2 - 4 } Calculated value & $S^{\prime}$ & $14999999.8698 \mathrm{~m}$ & $15999999.7987 \mathrm{~m}$ & $14999999.8352 \mathrm{~m}$ & $11661156.7269 \mathrm{~m}$ \\
& $A_{1}^{\prime}$ & $140^{\circ} 00^{\prime} 0.0009^{\prime \prime}$ & $90^{\circ} 00^{\prime} 00.0030^{\prime \prime}$ & $63^{\circ} 47^{\prime} 27.1704^{\prime \prime}$ & $0^{\circ} 00^{\prime} 00^{\prime \prime}$ \\
& $A_{2}^{\prime}$ & $294^{\circ} 46^{\prime} 41.4865^{\prime \prime}$ & $292^{\circ} 13^{\prime} 54.9185^{\prime \prime}$ & $269^{\circ} 59^{\prime} 59.9966$ & $180^{\circ} 00^{\prime} 00^{\prime \prime}$ \\
\hline \multirow{2}{*}{ Calculation deviation } & $\Delta_{S}$ & $0.126657848 \mathrm{~m}$ & $0.2023 \mathrm{~m}$ & $0.1648 \mathrm{~m}$ & $0.0019 \mathrm{~m}$ \\
& $\Delta_{A_{1}}$ & $0.0009^{\prime \prime}$ & $0.003141^{\prime \prime}$ & $0.000149^{\prime \prime}$ & $0.000^{\prime \prime}$ \\
& $\Delta_{A_{2}}$ & $0.002353^{\prime \prime}$ & $0.000565^{\prime \prime}$ & $0.003412^{\prime \prime}$ & $0.000^{\prime \prime}$ \\
\hline
\end{tabular}

The calculated values in Table 9 and the given conditions in reference [9] were reduced together by the nested coefficient DGPS. And then, the value computed and the error reduced between the that value and known condition are shown in Table 10.

Table 10. Statistics of reduction error in Example 5

\begin{tabular}{rccccc}
\hline Ellipsoid type & \multicolumn{2}{c}{ Hayford } & Krasovsky & Krasovsky & Krasovsky \\
\hline \multirow{2}{*}{ Reduced value } & $B_{2}^{\prime}$ & $-62^{\circ} 57^{\prime} 03.2027^{\prime \prime}$ & $-27^{\circ} 42^{\prime} 53.569^{\prime \prime}$ & $35^{\circ} 00^{\prime} 00^{\prime \prime}$ & $90^{\circ} 00^{\prime} 00^{\prime \prime}$ \\
& $L_{2}^{\prime}$ & $105^{\circ} 05^{\prime} 38.2895^{\prime \prime}$ & $173^{\circ} 13^{\prime} 02.5759^{\prime \prime}$ & $172^{\circ} 59^{\prime} 59.9929^{\prime \prime}$ & $70^{\circ} 00^{\prime} 00^{\prime \prime}$ \\
\hline \multirow{2}{*}{ Reduction error } & $\delta_{B_{2}^{\prime}}$ & $0.0011^{\prime \prime}$ & $0.000421^{\prime \prime}$ & $0.000^{\prime \prime}$ & $0.000^{\prime \prime}$ \\
& $\delta_{L_{2}^{\prime}}$ & $0.0099^{\prime \prime}$ & $0.008387^{\prime \prime}$ & $0.0071^{\prime \prime}$ & $0.000^{\prime \prime}$ \\
\hline
\end{tabular}

\section{Example 6}

The calculation values of example 6 obtained by Bessel's IGPS and the calculation deviation between the calculation value above and result of reference [10] are shown in Table 11.

Table 11. Statistics of calculation deviation in Example 6

\begin{tabular}{llllll}
\hline Ellipsoid type & Krasovsky & Krasovsky & Krasovsky & Krasovsky & GRS75 \\
\hline
\end{tabular}




\begin{tabular}{ccccccc}
\hline Calculated & $S^{\prime}$ & $80000.0000 \mathrm{~m}$ & $414303.9051 \mathrm{~m}$ & $7999606.1935 \mathrm{~m}$ & $15000000.1376 \mathrm{~m}$ & $10018758.6945 \mathrm{~m}$ \\
value & $A_{1}^{\prime}$ & $1^{\circ} 49^{\prime} 43.0018^{\prime \prime}$ & $36^{\circ} 12^{\prime} 01.9836^{\prime \prime}$ & $339^{\circ} 49^{\prime} 56.3847^{\prime \prime}$ & $100^{\circ} 00^{\prime} 00.3314^{\prime \prime}$ & $270^{\circ} 00^{\prime} 00.0021^{\prime \prime}$ \\
& $A_{2}^{\prime}$ & $181^{\circ} 50^{\prime} 53.547^{\prime \prime}$ & $218^{\circ} 11^{\prime} 27.7554^{\prime \prime}$ & $9^{\circ} 01^{\prime} 07.81^{\prime \prime}$ & $290^{\circ} 32^{\prime} 53.39^{\prime \prime}$ & $89^{\circ} 59^{\prime} 59.9979^{\prime \prime}$ \\
\hline \multirow{2}{*}{$\begin{array}{c}\text { Calculation } \\
\text { deviation }\end{array}$} & $\Delta_{S}$ & $0.0008 \mathrm{~m}$ & - & $0.2462 \mathrm{~m}$ & $0.1863 \mathrm{~m}$ & $0.1892 \mathrm{~m}$ \\
& $\Delta_{A_{1}}$ & $0.0001^{\prime \prime}$ & - & $0.0003^{\prime \prime}$ & $0.0039^{\prime \prime}$ & $0.0021^{\prime \prime}$ \\
\hline & $\Delta_{A_{2}}$ & $0.0001^{\prime \prime}$ & - & $0.0002^{\prime \prime}$ & $0.0018^{\prime \prime}$ & $0.0021^{\prime \prime}$ \\
\hline
\end{tabular}

The calculated values in Table 11 and the given conditions in reference [10] were reduced together by the nested coefficient DGPS. And then, the value computed and the error reduced between the that value and known condition are shown in Table 12.

Table 12. Statistics of reduction error in Example 6

\begin{tabular}{|c|c|c|c|c|c|c|}
\hline \multicolumn{2}{|c|}{ Ellipsoid type } & Krasovsky & Krasovsky & Krasovsky & Krasovsky & GRS75 \\
\hline \multirow{2}{*}{$\begin{array}{l}\text { Reduced } \\
\text { value }\end{array}$} & $B_{2}^{\prime}$ & $40^{\circ} 45^{\prime} 47.9027^{\prime \prime}$ & $43^{\circ} 00^{\prime} 55.8783^{\prime \prime}$ & $37^{\circ} 44^{\prime} 59.9833^{\prime \prime}$ & $-30^{\circ} 29^{\prime} 20.9644^{\prime \prime}$ & $0^{\circ} 00^{\prime} 00.0021^{\prime \prime}$ \\
\hline & $L_{2}^{\prime}$ & $130^{\circ} 12^{\prime} 01.104^{\prime \prime}$ & $118^{\circ} 10^{\prime} 02.9998^{\prime \prime}$ & $-122^{\circ} 26^{\prime} 0.0032^{\prime \prime}$ & $215^{\circ} 59^{\prime} 04.3294^{\prime \prime}$ & $10^{\circ} 00^{\prime} 00.0061^{\prime \prime}$ \\
\hline \multirow{2}{*}{$\begin{array}{l}\text { Reduction } \\
\text { error }\end{array}$} & $\delta_{B_{2}^{\prime}}$ & $0.000^{\prime \prime}$ & $0.0001^{\prime \prime}$ & $0.0078^{\prime \prime}$ & $0.0004^{\prime \prime}$ & $0.0021^{\prime \prime}$ \\
\hline & $\delta_{L_{2}^{\prime}}$ & $0.000^{\prime \prime}$ & $0.0002^{\prime \prime}$ & $0.0025^{\prime \prime}$ & $0.0086^{\prime \prime}$ & $0.0061^{\prime \prime}$ \\
\hline
\end{tabular}

\section{Example 7}

The calculation values of example 7 obtained by Bessel's IGPS and the calculation deviation between the calculation value above and result of reference [11] are shown in Table 13.

Table 13. Statistics of calculation deviation in Example 7

\begin{tabular}{|c|c|c|c|c|c|c|c|}
\hline Ellipsoid type & & Krasovsky & Krasovsky & Bessel & Krasovsky & Krasovsky & GRS75 \\
\hline \multirow{3}{*}{ Calculated value } & $S^{\prime}$ & 80000.0000 & 414306.5335 & 1320284.34845 & 7999606.1935 & 15000000.1376 & $10018758.6945 \mathrm{~m}$ \\
\hline & $A_{1}^{\prime}$ & $1^{\circ} 49^{\prime} 43.0018^{\prime \prime}$ & $36^{\circ} 12^{\prime} 01.0273^{\prime \prime}$ & $29^{\circ} 03^{\prime} 15.4594^{\prime \prime}$ & $339^{\circ} 49^{\prime} 56.3847^{\prime \prime}$ & $100^{\circ} 00^{\prime} 00.3314^{\prime \prime}$ & $270^{\circ} 00^{\prime} 00.0021^{\prime \prime}$ \\
\hline & $A_{2}^{\prime}$ & $181^{\circ} 50^{\prime} 53.547^{\prime \prime}$ & $218^{\circ} 11^{\prime} 26.797^{\prime \prime}$ & $216^{\circ} 45^{\prime} 07.4001^{\prime \prime}$ & $9^{\circ} 01^{\prime} 07.81^{\prime \prime}$ & $290^{\circ} 32^{\prime} 53.39^{\prime \prime}$ & $89^{\circ} 59^{\prime} 59.9979^{\prime \prime}$ \\
\hline \multirow{3}{*}{$\begin{array}{c}\text { Calculation } \\
\text { deviation }\end{array}$} & $\Delta_{S}$ & $0.000 \mathrm{~m}$ & $0.0497 \mathrm{~m}$ & $0.06975 \mathrm{~m}$ & $0.3067 \mathrm{~m}$ & $0.0723 \mathrm{~m}$ & $7.8535 \mathrm{~m}$ \\
\hline & $\Delta_{A_{1}}$ & $0.0002^{\prime \prime}$ & - & - & - & - & $0.0021^{\prime \prime}$ \\
\hline & $\Delta_{A_{2}}$ & $0.000^{\prime \prime}$ & - & - & $0.0056^{\prime \prime}$ & - & $0.0021^{\prime \prime}$ \\
\hline
\end{tabular}

The calculated values in Table 13 and the given conditions in reference [11] were reduced together by the nested coefficient DGPS. And then, the value computed and the error reduced between the that value and known condition are shown in Table 14.

Table 14. Statistics of reduction error in Example 7

\begin{tabular}{cccccccc}
\hline Ellipsoid type & & Krasovsky & Krasovsky & Bessel & Krasovsky & Krasovsky \\
& & & & & & & \\
& & & & & & & \\
Reduced value & $B_{2}^{\prime}$ & $40^{\circ} 45^{\prime} 47.9027^{\prime \prime}$ & $43^{\circ} 00^{\prime} 55.8783^{\prime \prime}$ & $54^{\circ} 59^{\prime} 59.9995^{\prime \prime}$ & $37^{\circ} 44^{\prime} 59.9833^{\prime \prime}$ & $-30^{\circ} 29^{\prime} 20.9644^{\prime \prime}$ & $00^{\circ} 00^{\prime} 00.0021^{\prime \prime}$ \\
& $L_{2}^{\prime}$ & $130^{\circ} 12^{\prime} 01.104^{\prime \prime}$ & $118^{\circ} 10^{\prime} 02.9998^{\prime \prime}$ & $9^{\circ} 59^{\prime} 59.9991^{\prime \prime}$ & $-122^{\circ} 26^{\prime} 00.0032^{\prime \prime}$ & $215^{\circ} 59^{\prime} 04.3294^{\prime \prime}$ & $10^{\circ} 00^{\prime} 00.0061^{\prime \prime}$ \\
\hline
\end{tabular}




\begin{tabular}{|c|c|c|c|c|c|c|c|}
\hline \multirow{2}{*}{ Reduction error } & $\delta_{B_{2}^{\prime}}$ & $0.000^{\prime \prime}$ & $0.0001^{\prime \prime}$ & $0.0005^{\prime \prime}$ & $0.0078^{\prime \prime}$ & $0.0004^{\prime \prime}$ & $0.0021^{\prime \prime}$ \\
\hline & $\delta_{L_{2}}$ & $0.000^{\prime \prime}$ & $0.0002^{\prime \prime}$ & $0.0009^{\prime \prime}$ & $0.0025^{\prime \prime}$ & $0.0086^{\prime \prime}$ & $0.0061^{\prime \prime}$ \\
\hline
\end{tabular}

\section{Example 8}

The calculation values of example 8 obtained by Bessel's IGPS and the calculation deviation between the calculation value above and result of reference [12] are shown in Table 15.

Table 15. Statistics of calculation deviation in Example 8

\begin{tabular}{ccccccc}
\hline \multicolumn{2}{c}{ Ellipsoid type } & Krasovsky & Krasovsky & Krasovsky & Krasovsky & GRS75 \\
\hline $\begin{array}{c}\text { Calculated } \\
\text { value }\end{array}$ & $S^{\prime}$ & $99999.9775 \mathrm{~m}$ & $499999.9522 \mathrm{~m}$ & $4999997.8604 \mathrm{~m}$ & $16000000.2152 \mathrm{~m}$ & $10018758.6945 \mathrm{~m}$ \\
& $A_{1}^{\prime}$ & $270^{\prime} 22^{\prime} 37.0085^{\prime \prime}$ & $88^{\circ} 42^{\prime} 13.4074^{\prime \prime}$ & $60^{\circ} 33^{\prime} 17.2754^{\prime \prime}$ & $5^{\circ} 07^{\prime} 45.6827^{\prime \prime}$ & $270^{\circ} 00^{\prime} 00.0021^{\prime \prime}$ \\
& $A_{2}^{\prime}$ & $89^{\prime} 37^{\prime} 22.9915^{\prime \prime}$ & $271^{\circ} 17^{\prime} 46.5926^{\prime \prime}$ & $299^{\circ} 26^{\prime} 42.7246^{\prime \prime}$ & $302^{\circ} 52^{\prime} 14.3173^{\prime \prime}$ & $89^{\circ} 59^{\prime} 59.9979^{\prime \prime}$ \\
\hline $\begin{array}{c}\text { Calculation } \\
\text { deviation }\end{array}$ & $\Delta_{S}$ & $0.0245 \mathrm{~m}$ & $0.0488 \mathrm{~m}$ & - & $0.2142 \mathrm{~m}$ & $0.1893 \mathrm{~m}$ \\
& $\Delta_{A_{1}}$ & $0.0005^{\prime \prime}$ & $0.0004^{\prime \prime}$ & $0.0004^{\prime \prime}$ & $0.0053^{\prime \prime}$ & $0.0021^{\prime \prime}$ \\
\hline$\Delta_{A_{2}}$ & $0.0005^{\prime \prime}$ & $0.0004^{\prime \prime}$ & $0.0004^{\prime \prime}$ & $0.0053^{\prime \prime}$ & $0.0021^{\prime \prime}$ \\
\hline
\end{tabular}

The calculated values in Table 15 and the given conditions in reference [12] were reduced together by the nested coefficient DGPS. And then, the value computed and the error reduced between the that value and known condition are shown in Table 16.

Table 16. Statistics of reduction error in Example 8

\begin{tabular}{|c|c|c|c|c|c|c|}
\hline \multicolumn{2}{|c|}{ Ellipsoid type } & Krasovsky & Krasovsky & Krasovsky & Krasovsky & GRS75 \\
\hline \multirow{2}{*}{$\begin{array}{l}\text { reduced } \\
\text { value }\end{array}$} & $B_{2}^{\prime}$ & $40^{\circ} 02^{\prime} 35.6784^{\prime \prime}$ & $30^{\circ} 00^{\prime} 00.0000^{\prime \prime}$ & $50^{\circ} 00^{\prime} 00.001^{\prime \prime}$ & $10^{\circ} 00^{\prime} 00.0063^{\prime \prime}$ & $00^{\circ} 00^{\prime} 00.0021^{\prime \prime}$ \\
\hline & $L_{2}^{\prime}$ & $128^{\circ} 59^{\prime} 53.8816^{\prime \prime}$ & $20^{\circ} 29^{\prime} 57.9771^{\prime \prime}$ & $101^{\circ} 01^{\prime} 22.9519^{\prime \prime}$ & $164^{\circ} 55^{\prime} 53.9923^{\prime \prime}$ & $10^{\circ} 00^{\prime} 00.0061^{\prime \prime}$ \\
\hline \multirow{2}{*}{$\begin{array}{l}\text { Reduction } \\
\text { error }\end{array}$} & $\delta_{B_{2}^{\prime}}$ & $0.000^{\prime \prime}$ & $0.000^{\prime \prime}$ & $0.001^{\prime \prime}$ & $0.0063^{\prime \prime}$ & $0.0021^{\prime \prime}$ \\
\hline & $\delta_{L_{2}^{\prime}}$ & $0.000^{\prime \prime}$ & $0.0002^{\prime \prime}$ & $0.0041^{\prime \prime}$ & $0.0057^{\prime \prime}$ & $0.0061^{\prime \prime}$ \\
\hline
\end{tabular}

\section{Conclusion}

Aiming at the reality that marine delimitation involve in a large geographical area, from the perspective of basic principle, calculation steps, algorithm characteristics and theoretical accuracy, we systematically expound the application of the nested coefficient method and Bessel's formula in the direct and inverse calculation of the geodetic problem. As the mathematical basis of the underlying technology of marine delimitation on the earth ellipsoid surface, the most significant advantage of the two proposed algorithms is that they are applicable to any distance. With help of the specific examples, the accuracy of the two solution algorithms with different principles are verified by the way of crossover and reduction, and the correctness and precision of each algorithm are tested effectively. The experimental results show that the precision of point plotting, distance and azimuth calculating can meet the requirement of the absolute precision of marine delimitation on earth ellipsoid surface well.

\section{Acknowledgments}

Foundation support: The National Key R\&D Program of China, No. 2017YFC1405505; The National Natural Science Foundation of China (42071439, 41871369 and 41901320).

\section{References}

1. Zhenghang Li, Erhu Wei, Zhengtao Wang, et al. (2010) Space Geodesy. Wuhan University Press. Wuhan.

2. Jiwen Huang, (1991). Ellipsoidal Geodesy. Surveying and Mapping Academy of PLA. Zhengzhou.

3. Tang Hua, (1985). Mathematical Foundations of Charts. Maritime Assurance Department of the Naval 
Command of the Chinese People's Liberation Army.

4. Hongtao Tang, Wei Wang, Chongyong Yang, et al. (2015) An Algorithm of Expressing Geodesic on Ellipsoid Surface. J. Science of Survying and Mapping, 40(4): 7-10.

5. Zhigang Su, Guangchao Wang, Jingtang Hao. (2016) 3D Visualization of Dynamic Flight Information Based on Great Circle Routine. J. Computer Measurement \& Control, 24(8): 233-235, 262.

6. Tengfei Wu. (2015) Study on Method of Expressing Earth Object in Large Based on Ellipsoid Surface. D. Xi'an University of Science and Technology, Xi'an.

7. Shaofeng Bian, Houpu Li, (2018). Computer Algebra Analysis on Geodesy. Science Press. Beijing.

8. Shaofeng Bian, Jiangning $\mathrm{Xu}$, (2004). Computer Algebra System and Mathematical Analysis of Geodetics. National Defense Industry Press. Beijing.

9. Guoyou Shi, Xiaoming Zhou, chuanying Jia. (2008) Improved algorithm for direct solution of Bessel's geodetic problem. J. Journal of Dalian Maritime University, 34(1): 15-19.

10. Xiaohan Xu, Yunkai Xie, Yajun Li.( 2012) A Practical Algorithm for Solution of Geodetic Problem. J. Science Technology and Engineering, 12(36): 2062-2068.

11. Ju He, Peng Hu, Hai Hu.( 2006) Investigation and experiment of algorithm fitting arbitrary distance. J. Science of Survying and Mapping, 31(2): 29-32.

12. Aisheng Wang, Huan $\mathrm{Xu}$, Qi Zhang, Meng Wei, (2015) Practical Formulas for Geodetic Based on CGCS2000 Ellipsoid. J. Journal of Navigation and Positioning, 3(3): 105-131. 